\title{
SIMULATION OF CURRENT-VOLTAGE CHARACTERISTICS OF SINGLE ELECTRON TRANSISTOR USING NEMO-VN2
}

\author{
Dinh Sy Hien \\ University of Science, VNU-HCM \\ (Manuscript Received on November 14 $4^{\text {th }}, 2011$, Manuscript Revised September 11 ${ }^{s t}, 2012$ )
}

ABSTRACT: We have developed a simulator for nanoelectronics devices, NEMO-VN2. In this work we use the simulator to explore the performance of single electron transistor. The model is based on non-equilibrium Green function method and implemented by using graphic user interface of Matlab. The current-voltage characteristics such as drain current-voltage, drain current-gate voltage ones are explored. Some characteristics reproduced by the proposed model are compared with experimental results of single electron transistor and good agreements are validated.

Keywords: single electron transistor, non-equilibrium Green function, current-voltage characteristic, Coulomb blockage, Coulomb oscillation.

\section{INTRODUCTION}

Rapid progress in microelectronics has pushed the MOSFET dimension toward the physical limit $(10 \mathrm{~nm})$. In the future it is probable that the nanoMOSFETs could be replaced by new fundamental devices, such as single electron transistor (SET). SETs have attracted much attention for IC applications because of their nano feature size, ultra-low power dissipation, high frequency, new functionalities, and CMOS compatible fabrication process. SET shows unique advantages in terms of low power consumption and of new characteristics related to its Coulomb oscillations and Coulomb blockade. Recently, there are various groups achieving success in pursuing to build simulator for SET $[1,2]$. The Monte Carlo simulations (e.g. SIMON [3], MOSES [4], and KOSEC [5]) and master equation methods $[6,7]$ that are quite accurate but also very time consuming, and they are not simple. In contrast, model used non-equilibrium Green function method (NEGF) [8] commonly used in the nanoscale devices and are superior in terms of simplicity.

In this work, we simulate current-voltage characteristics in single electron transistor by non-equilibrium Green function method using graphic user interface (GUI) of Matlab. Here, we use a model of multi level device for SET (i.e. it takes quantumization into account). We also summarize the theoretical approach based on NEGF, review the capabilities of the simulator, NEMO-VN2 [9], give examples of typical simulations of SET's current-voltage characteristics, and compare simulated results with experimental ones.

\section{METHODS}


A model of single electron transistor usually called a capacitance model is shown in figure 1. A SET is made from two tunnel junctions that share a common electrode. A tunnel junction consists of two pieces of metal supported by a very thin (about $1 \mathrm{~nm}$ ) insulator. The only way for electrons is from one of the metal electrodes to travel to the other electrode is to tunnel through the insulator. Since tunneling is a discrete process, the electric charge that flows through the tunnel junction in multiples of e, the charge of electron.

A quantum dot (QD) is usually formed in two dimensional electron gas (2DEG) in $\mathrm{GaAs} / \mathrm{AlGaAs}$ using standard electron beam lithography. The quantum dot is connected to the source and drain electrodes through tunnel barriers. The potential in the dot can be controlled by the gate electrode which is

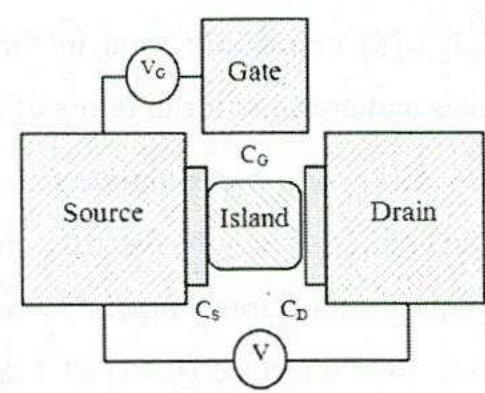

(a) capacitively coupled to the quantum dot (Figure $1 b$ ). The current through the quantum dot can be periodically modulated by the gate voltage $\left(\mathrm{V}_{\mathrm{G}}=(2 \mathrm{n}+1) \times \mathrm{e} / 2 \mathrm{C}_{\mathrm{G}}\right.$, Coulomb oscillations). When the current is zero (Coulomb blockade, CB), the number of electrons is fixed. Therefore it differs exactly by one on both sides of the current peak.

A proper operation of a SET device requires: 1) the tunnel junction resistances (drain resistance, $R_{D}$ and source resistance, $R_{S}$ ) to be greater than the quantum resistance $(25.8$ $\mathrm{k} \Omega$ ) to confine the electrons in the quantum dot, 2) the charging energy of the QD capacitance to be larger than the available thermal energy to avoid electron tunneling due to the thermal emission, and the total capacitance is equal to the summation of all device capacitances, i.e. $C_{T}=C_{G}+C_{D}+C_{S}$.

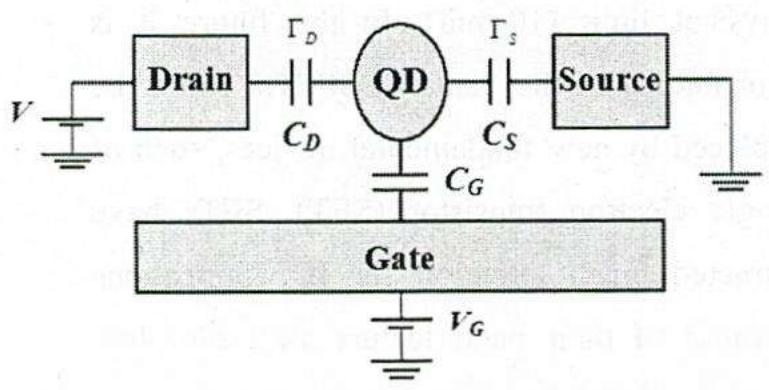

(b)

Figure 1. a) Structure of single electron transistor, b) equivalent schematic diagram of SET. The quantum dot is connected to the source and drain electrodes through small tunnel barriers. The potential in the quantum dot can be modified by the gate electrode which is capacitively coupled to the quantum dot $\left(V_{G}=(2 n+1) e / 2 C_{G}\right)$. The $D C$ bias $\left(V_{D}\right)$ is applied and the current is measured as a function of $V_{D}$ and $V_{G}$. The SET's parameters are: $C_{S}, C_{D}$, $\mathrm{C}_{\mathrm{G}}, \Gamma_{\mathrm{S}}, \Gamma_{\mathrm{D}}$.

We describe a SET's model for a multi level device whose energy levels are described by a Hamiltonian matrix $[\mathrm{H}]$ and whose coupling to the source and the drain contacts is described by selfenergy matrices $\left[\sum_{1}(E)\right\rfloor$ and $\left[\sum_{2}(E)\right]$ respectively (Figure 2). 


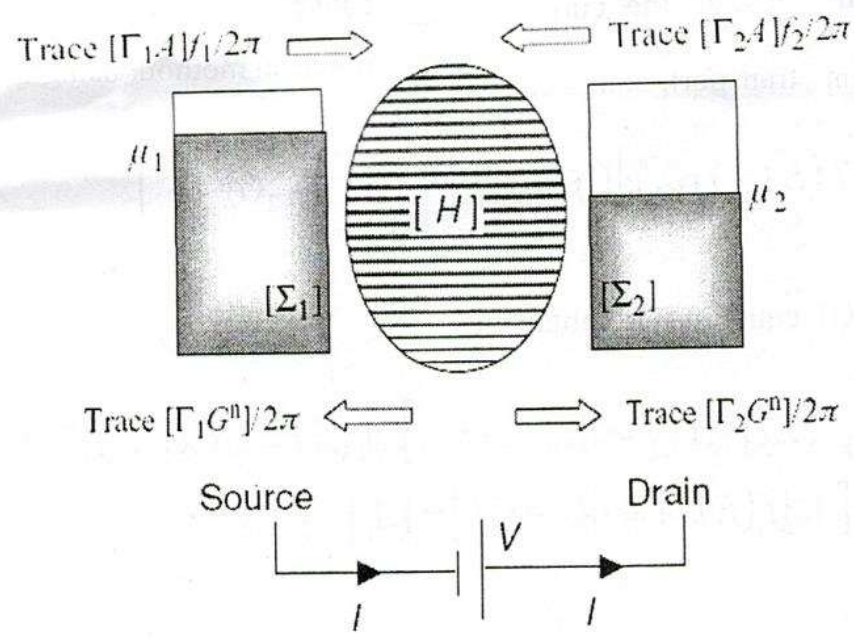

Figure 2. Multi-level device whose energy levels are described by a Hamiltonian matrix $[\mathrm{H}]$ and whose coupling to the source and drain contacts is described by self-energy matrices $\left[\sum_{1}(E)\right]$ and $\left[\sum_{2}(E)\right]$ respectively.

The flow of current is due to the difference in potentials between the source and the drain, each of which is in a state of local equilibrium, but maintained at different electro-chemical potentials $\mu_{1,2}$ and hence with two distinct Fermi functions:

$$
\begin{aligned}
f_{1}(E) & \equiv f_{0}\left(E-\mu_{1}\right)=\frac{1}{\exp \left[\left(E-\mu_{1}\right) / k_{B} T\right]+1} \\
f_{2}(E) \equiv f_{0}\left(E-\mu_{2}\right) & =\frac{1}{\exp \left[\left(E-\mu_{2}\right) / k_{B} T\right]+1}
\end{aligned}
$$

by the applied bias $\mathrm{V}$ : $\mu_{2}-\mu_{1}=-q V$. Here, E- energy, $\mathrm{k}_{\mathrm{B}}$ - Boltzmann constant, $\mathrm{T}$ - temperature.

The density matrix is given by

$$
\rho=\int_{-\infty}^{+\infty} \frac{d E}{2 \pi} G^{n}(E)=\int_{-\infty}^{+\infty} \frac{d E}{2 \pi}\left[A_{1}(E) f_{1}(E)+A_{2}(E) f_{2}(E)\right]
$$

The current $\mathrm{I}_{\mathrm{D}}$ flows in the external circuit is given by Landauer formula [8]:

$$
I_{D}=(q / h) \int_{-\infty}^{+\infty} d E T(E)\left(f_{1}(E)-f_{2}(E)\right)
$$

The quantity $\mathrm{T}(\mathrm{E})$ appearing in the current equation (4) is called the transmission function, which tells us the rate at which electrons transmit from the source to the drain contacts by propagating through the device. Knowing the device Hamiltonian $[\mathrm{H}]$ and its coupling to the contacts described by the self-energy 
matrices $\Sigma_{1,2}$, we can calculate the current from (4). For coherent transport, one can calculate the transmission from the Green's function method, using the relation

$$
\left.\left.T(E)=\operatorname{Trace} \mid \Gamma_{1} G \Gamma_{2} G^{+}\right\rfloor=\operatorname{Trace} \mid \Gamma_{2} G \Gamma_{1} G^{+}\right\rfloor
$$

The appropriate NEGF equations are obtained:

$$
\begin{aligned}
& G=\left[E I-H-\Sigma_{1}-\Sigma_{2}\right]^{-1}, \Gamma_{1,2}=i\left[\Sigma_{1,2}-\Sigma_{1,2}^{+}\right], A_{1}(E)=G \Gamma_{1} G^{+}, A_{2}(E)=G \Gamma_{2} G^{+}, \\
& G^{n}=\left[A_{1}\right] f(E)+\left[A_{2}\right] f(E), A \equiv i\left[G-G^{+}\right]=\left[A_{1}\right]+\left[A_{2}\right]
\end{aligned}
$$

Where $\mathrm{H}$ is effective mass Hamiltonian, $\mathrm{I}$ is an identity matrix of the same size, $\Gamma_{1,2}$ are the broadening functions, $A_{1,2}$ are partial spectral functions, $\mathrm{A}(\mathrm{E})$ are spectral function,
$\mathrm{G}^{\mathrm{h}}$ is correlation function. We use a discrete lattice with $\mathrm{N}$ points spaced by lattice spacing a to calculate the eigenenergies for electrons in the quantum dot. The Hamiltonian $\mathrm{H}$ is given by

$$
H=\begin{array}{cccccc} 
& 1 & 2 & \ldots & N-1 & N \\
1 & 2 t_{0} & -t_{0} & & 0 & 0 \\
2 & -t_{0} & 2 t_{0} & & 0 & 0 \\
\cdots & \cdots & \cdots & \cdots & \ldots & \ldots \\
N-1 & 0 & 0 & & 2 t_{0} & -t_{0} \\
N & 0 & 0 & & -t_{0} & 2 t_{0}
\end{array}
$$

where $t_{0}=\frac{\hbar^{2}}{2 m a^{2}}, \mathrm{~m}$ is the effective mass of electron, $\hbar$ is the modified plank constant, $a$ is the lattice spacing in quantum dot.

By utilizing the simulator namely NEMOVN2, the $I_{D}-V_{G}$ characteristics of SET having the given parameters are shown in Figure 3.

\section{RESULTS AND DISCUSSION}




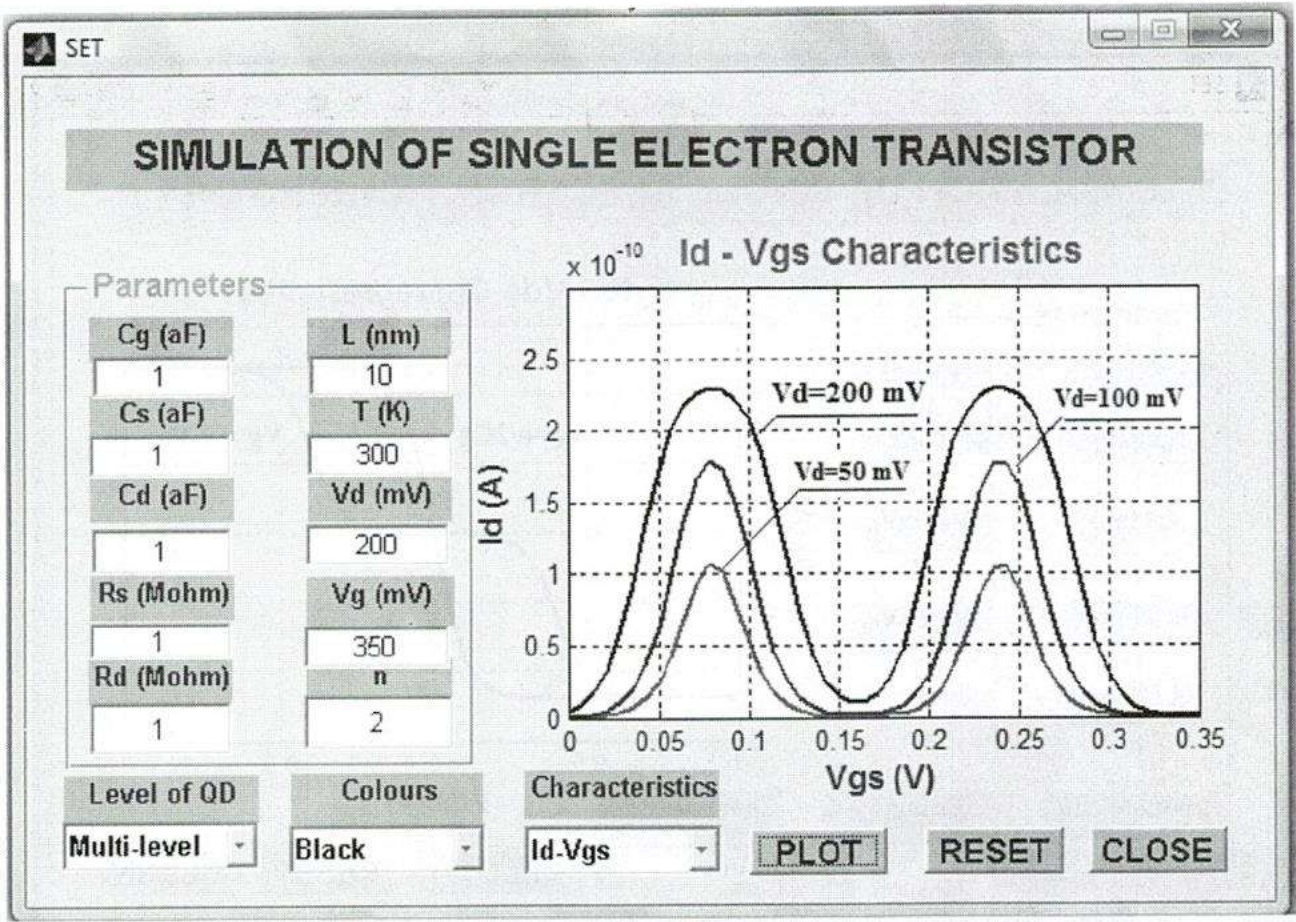

Figure 3. Typical $I_{D}-V_{G}$ characteristics (Coulomb oscillations) of SET simulated by the simulator NEMOVN2 for various values of $\mathrm{V}_{\mathrm{D}}=50 \mathrm{mV}, 100 \mathrm{mV}$ and $200 \mathrm{mV}$ at room temperature, $\mathrm{T}=300 \mathrm{~K}$. The SET device parameters are: $\mathrm{L}=10 \mathrm{~nm}, \mathrm{C}_{\mathrm{G}}=\mathrm{C}_{\mathrm{S}}=\mathrm{C}_{\mathrm{D}}=1 \mathrm{aF}$ and $\mathrm{R}_{\mathrm{S}}=\mathrm{R}_{\mathrm{D}}=1 \mathrm{M} \Omega$.

Figure 3 demonstrates the typical Coulomb oscillation behavior in SET $\mathrm{I}_{\mathrm{D}}-\mathrm{V}_{\mathrm{G}}$ characteristics. It shows that the SET Coulomb oscillation period $\left(e / \mathrm{C}_{\mathrm{G}}\right.$, e is the electronic charge) is dictated by SET's gate capacitance. Values of gate voltage at the first and the second peaks are $\mathrm{e} / 2 \mathrm{C}_{\mathrm{G}}(80 \mathrm{mV})$ and $3 \mathrm{e} / 2 \mathrm{C}_{\mathrm{G}}$ $(240 \mathrm{mV})$ respectively. Here, it should be emphasized that the peak and the valley currents of Coulomb oscillations are perfectly represented by the model. The results calculated according to model $\left(\mathrm{e} / 2 \mathrm{C}_{\mathrm{G}}\right.$ for $\mathrm{C}_{\mathrm{G}}=$ $1 \mathrm{aF}$ ) coincide well with the simulated ones. Current-voltage $\quad\left(\mathrm{I}_{\mathrm{D}}-\mathrm{V}_{\mathrm{G}}\right) \quad$ characteristics showing the suppression of the Coulomb oscillation by broadening current peaks increased at high $V_{D}(200 \mathrm{mV})$. It also reveals the fact that it is difficult to obtain the Coulomb oscillations in the device characteristics at high $V_{D}$ greater than $3 \mathrm{e} / \mathrm{C}_{\mathrm{T}}\left(\mathrm{C}_{\mathrm{T}}\right.$ is total capacitance of SET), $(160 \mathrm{mV})$. It should note that high drain voltage, $V_{D}$ undermines SET's currentvoltage characteristics.

Figure 4 reproduces SET's $I_{D}-V_{D}$ characteristics at room temperature $(T=300 \mathrm{~K})$ for different gate biases, $\mathrm{V}_{\mathrm{G}}=0 \mathrm{mV}$ and $\mathrm{V}_{\mathrm{G}}=$ $\mathrm{e} / 2 \mathrm{C}_{\mathrm{G}}$ (Coulomb oscillation). For $\mathrm{V}_{\mathrm{G}}=0 \mathrm{mV}$, $V_{D}$ starts from the Coulomb blockage (CB) region and increases (or decreases) through the single-electron tunneling region. For $\mathrm{V}_{\mathrm{G}}=$ $\mathrm{e} / 2 \mathrm{C}_{\mathrm{G}}$ (at the first Coulomb oscillation peak), $I_{D}$ starts from zero and increases (or decreases) linearly. 


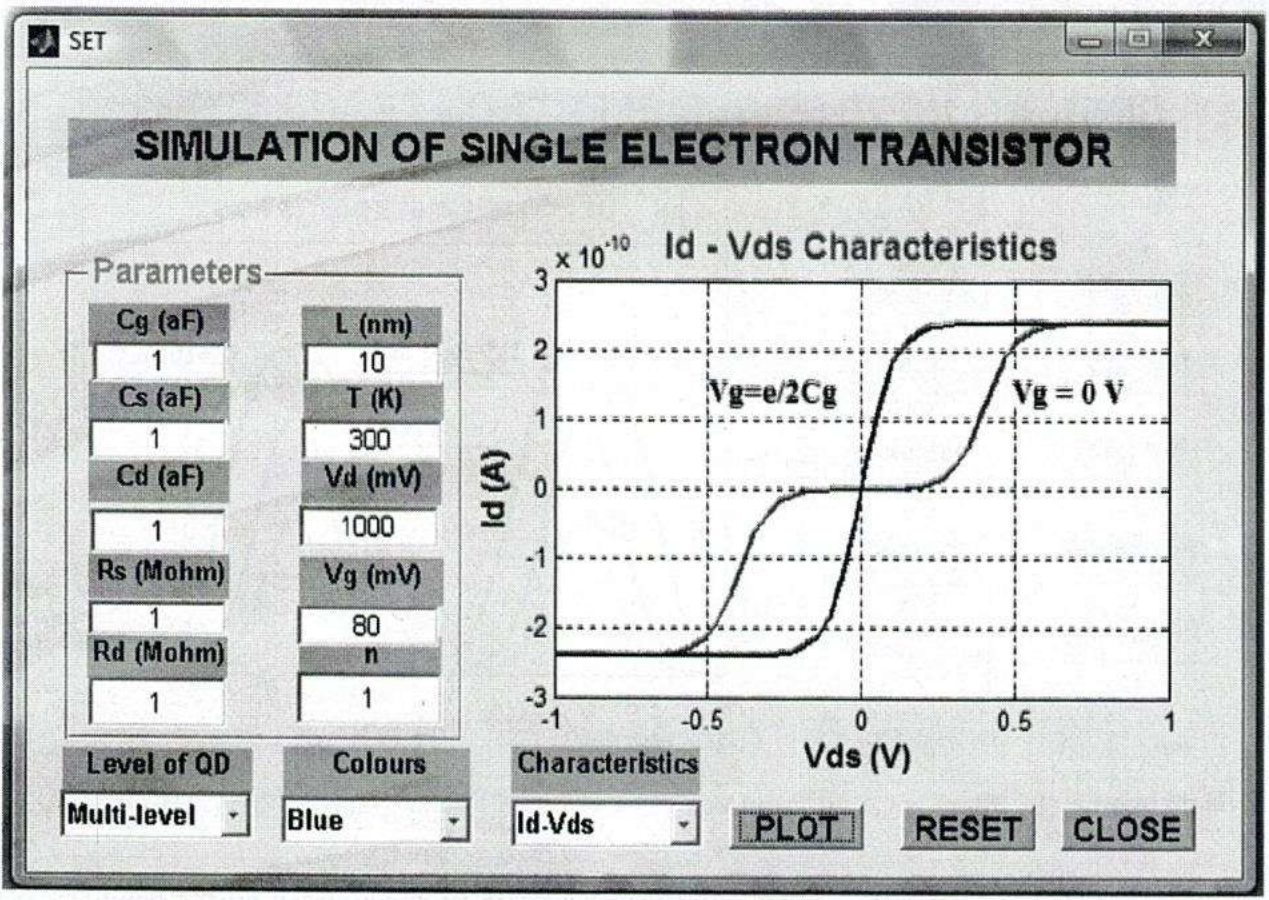

Figure 4. $I_{D}-V_{D}$ characteristics simulated by the simulator at room temperature $T=300 \mathrm{~K}$ for various values of $\mathrm{V}_{\mathrm{G}}=0 \mathrm{mV}$ and $\mathrm{V}_{G}=\mathrm{e} / 2 \mathrm{C}_{G}$. The SET device parameters are: $\mathrm{L}=10 \mathrm{~nm}, \mathrm{C}_{\mathrm{G}}=\mathrm{C}_{\mathrm{S}}=\mathrm{C}_{\mathrm{D}}=1 \mathrm{aF}$ and $\mathrm{R}_{\mathrm{S}}=\mathrm{R}_{\mathrm{D}}=1$ $\mathrm{M} \Omega$.

Figure 5 represents $I_{D}-V_{G}$ characteristics with the value of $V_{D}=10 \mathrm{mV}$ at different temperatures. One can note that the effects of temperature on Coulomb oscillations are strongly. The Coulomb oscillations of SET are clear at low temperature (at $50 \mathrm{~K}$ ). Currentvoltage $\left(I_{D}-V_{G}\right)$ characteristics showing the suppression of the Coulomb oscillation by broadening current peaks increased at higher temperature $(100 \mathrm{~K}, 200 \mathrm{~K}$, and $300 \mathrm{~K})$. It also reveals the fact that it is no more possible to obtain the Coulomb oscillations in the device characteristics at high temperature. It should note that high temperature undermines SET's current-voltage characteristics. 


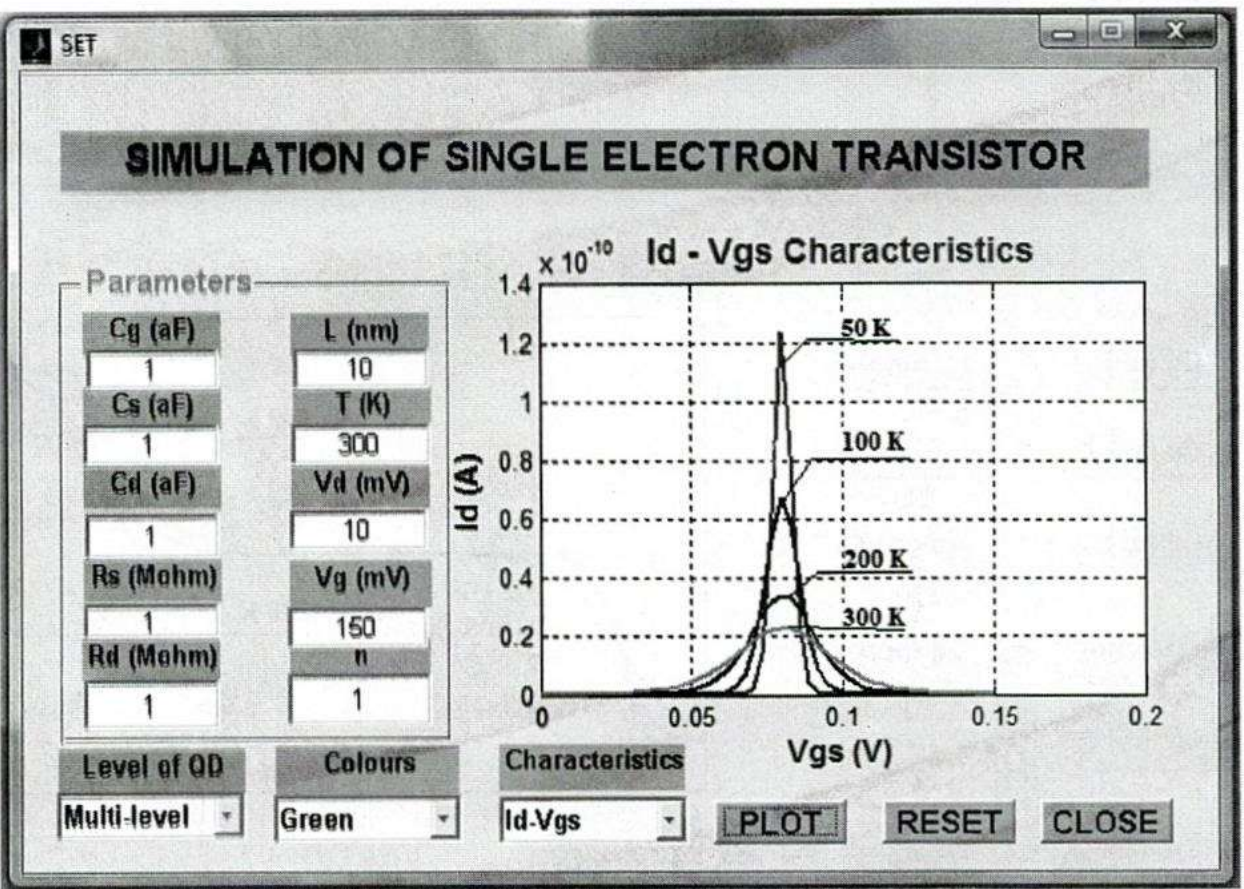

Figure 5. Typieal $\mathrm{I}_{\mathrm{D}} \cdot \mathrm{V}_{\mathrm{G}}$ characteristics simulated by the simulator for value of $\mathrm{V}_{\mathrm{D}}=10 \mathrm{mV}$ at different temperatures: $50 \mathrm{~K}, 100 \mathrm{~K}, 200 \mathrm{~K}, 300 \mathrm{~K}$. The SET device parameters are: $\mathrm{L}=10 \mathrm{~nm}, \mathrm{C}_{\mathrm{G}}=\mathrm{C}_{\mathrm{S}}=\mathrm{C}_{\mathrm{D}}=1 \mathrm{aF}$ and

$$
\mathrm{R}_{\mathrm{S}}=\mathrm{R}_{\mathrm{D}}=1 \mathrm{M} \Omega
$$

The effect of temperature (T) on the device characteristics is also demonstrated in Figure 6, and it shows that the Coulomb blockade region becomes thinner at higher temperatures.
Therefore, an accurate model for SET simulation must be to capture both the effect of temperature and the effect of high $V_{D}$ on the device characteristics. 


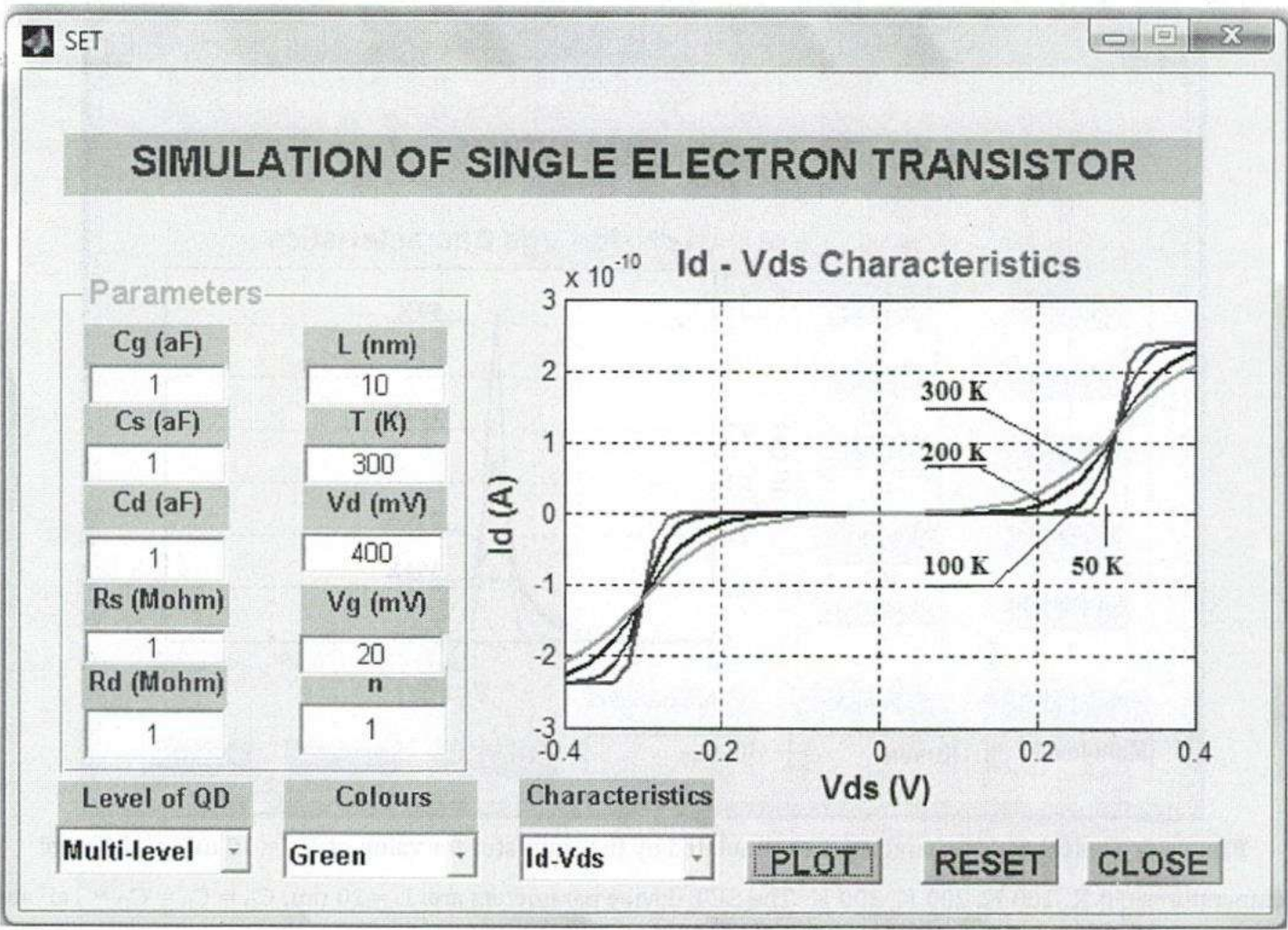

Figure 6. Typical $I_{D}-V_{D}$ characteristics simulated by the simulator for value of $V_{G}=20 \mathrm{mV}$ at different temperatures (T): $50 \mathrm{~K}, 100 \mathrm{~K}, 200 \mathrm{~K}$, and $300 \mathrm{~K}$. The SET device parameters are: $\mathrm{L}=10 \mathrm{~nm}, \mathrm{C}_{\mathrm{G}}=\mathrm{C}_{\mathrm{S}}=\mathrm{C}_{\mathrm{D}}$ $=1 \mathrm{aF}$ and $\mathrm{R}_{\mathrm{S}}=\mathrm{R}_{\mathrm{D}}=1 \mathrm{M} \Omega$.

Accuracy of the model is evaluated by comparing simulated results with experimental ones from [10].

According to the work [10], its authors have succeeded in fabricating an SET. The SET operates at room temperature, showing a clear Coulomb staircase with a $\sim 150 \mathrm{mV}$ period at $300 \mathrm{~K}$. The drain current-voltage characteristics of the SET were measured at room temperature and are shown in figure $7 \mathrm{a}$. The gate bias was set to $2 \mathrm{~V}$. In the figure, the solid lines show the current of the SET, and the dashed line shows the conductance of the SET. Between the drain bias of $0 \mathrm{~V}$ and $-0.75 \mathrm{~V}$, four clear Coulomb staircases with a $\sim 150 \mathrm{mV}$ period are observed. The conductance oscillates with the increase of the drain bias with almost the same $150 \mathrm{mV}$ period. The lower peaks of the conductance oscillation correspond to the flat regions of the current of the Coulomb staircase. The drain current versus gate bias characteristics with $150 \mathrm{mV}$ drain bias at room temperature exhibit clear current oscillations with a period of $\sim 460 \mathrm{mV}$, implying a periodic Coulomb oscillation of the current. The tunneling capacitance $\left(\mathrm{C}_{\mathrm{t}}\right)$ and gate capacitance $\left(\mathrm{C}_{\mathrm{g}}\right)$ could be roughly estimated from the period of the Coulomb staircase and oscillation. Their values were found to be $\mathrm{C}_{\mathrm{t}}=\sim 3.6 \times 10^{-19} \mathrm{~F}$ and $\mathrm{C}_{\mathrm{G}}=\sim 3.5 \mathrm{x}$ $10^{-19} \mathrm{~F}$.

\section{Trang 22}


Figure $7 b, c$ reproduce $I_{D}-V_{D}$ characteristics and conductance of the same SET having length, $\mathrm{L}=10 \mathrm{~nm}$ at temperature of $300 \mathrm{~K}$. Figures $7 b, c$ show simulated results of $I_{D}-V_{D}$ characteristics and conductance of the same SET. Four clear Coulomb staircases are shown in simulated results on $I_{D}-V_{D}$ characteristics (Figure $7 \mathrm{~b}$ ). Four clear conductance peaks are also shown in Figure 7c. The results simulated according to the model coincide well with the experimental ones at least in the same shape.

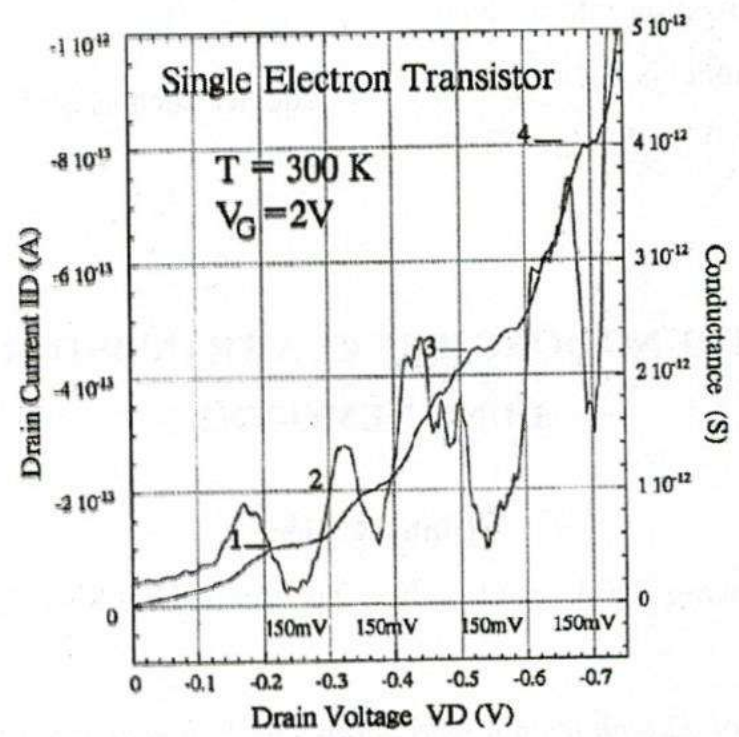

a)

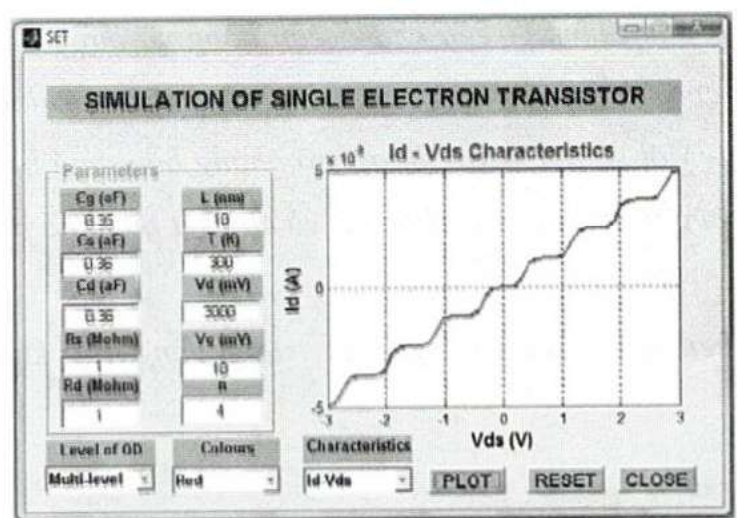

b)

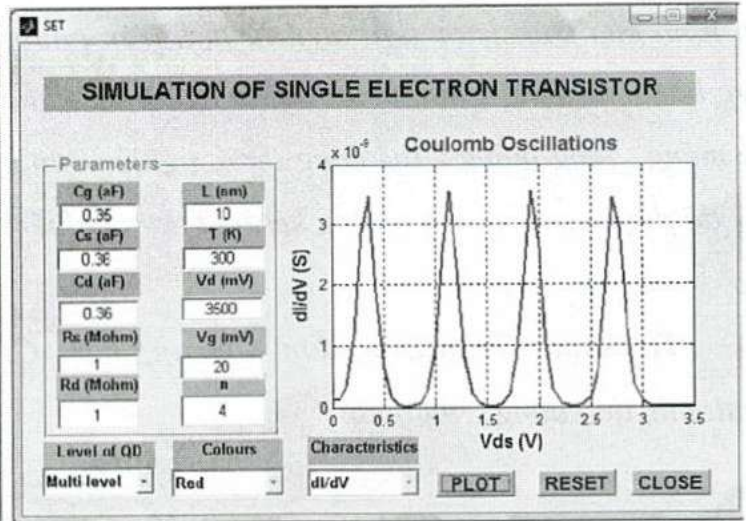

c)

Figure 7, a) Drain current versus drain voltage characteristics of the SET at $300 \mathrm{~K}[10]: \mathrm{V}_{\mathrm{D}}=150 \mathrm{mV}, \mathrm{C}_{\mathrm{t}}=0.36$ $\left.\mathrm{aF}, \mathrm{C}_{\mathrm{g}}=0.35 \mathrm{aF} ; \mathrm{b}\right) \mathrm{I}_{\mathrm{D}} \cdot \mathrm{V}_{\mathrm{D}}$ characteristics simulated; c) Conductance characteristics simulated by the simulator, NEMO-VN2 for value of $V_{G}=20 \mathrm{mV}$. The SET device parameters are: $\mathrm{L}=10 \mathrm{~nm}, \mathrm{C}_{\mathrm{G}}=0.35 \mathrm{aF}, \mathrm{C}_{\mathrm{S}}=\mathrm{C}_{\mathrm{D}}=0.36$ $\mathrm{aF}$ and $\mathrm{R}_{\mathrm{S}}=\mathrm{R}_{\mathrm{D}}=1 \mathrm{M} \Omega$. 


\section{CONCLUSION}

A model for SET device using NEGF written in GUI of Matlab has been reported. The proposed model has been verified at multi level for SET's device. A set of simulations is then successfully performed for various parameters of the SET's device in multi-level mode (i.e. it takes quantumization into account in the quantum dot). The model is not only able to accurately describe $I_{D}-V_{G}, I_{D}-V_{D}$ SET's characteristics, but also affects of gate materials, size of SET, temperature on SET's characteristics. Different SET's device characteristics $\left(I_{D}-V_{G}, \quad I_{D}-V_{D}\right.$, effect of temperature) have been simulated. The simulated results are also compared with experimental ones [10] and good agreements are validated. NEMO-VN2 is a good tool for the development and investigation of quantum device such as SET.

\title{
MÔ PHỎNG ĐẶC TRƯ'NG DÒNG-THÉ CỦA TRANSISTOR ĐƠN ĐIỆN TỬ SỬ DỤNG NEMO-VN2
}

\author{
Đinh Sỹ Hiền \\ Trường Đại học Khoa học Tự nhiên, ĐHQG-HCM
}

TÓM TÄT: Chüng tôi đã phát triển bộ mô phòng cho linh kiện điện tic nano, NEMO-VN2. Trong công trình này, chúng tôi sủ dụng bộ mô phỏng để nghiên cứu kỹ đặc tính cuia transistor đơn điện tủ. Mô hình của transistor đơn điện tư dụa trên phương pháp hàm Green không cân bằng và được hiện thụcc bằng sủ dụng giao diện đồ họa người sủ dụng của Matlab. Nhũ̃ng đặc trưng dòng-thế nhu dòng thế máng, dòng máng - thế cổng được nghiên cúu kỹ. Một số đặc trung đurợc mô phỏng bằng mô hinh này đã được so sánh với nhũng kết quả thụ̂c nghiệm của transistor đơn điện tủ và cho kết quả khá phù hợp.

Tù̀ khóa: Transistor đơn điện tủ, hàm Green không cân bằng, đặc trung dòng-thế, khóa Coulomb, dao động Coulomb.

\section{REFERENCES}

[1] K. Uchida, R. Matsuzawa, J. Koga, R. Ohba, S. Takagi, A. Toriumi, Analytical single electron transistor (SET) model for design and analysis of realistic SET circuits, Jpn. J. Appl. Phys., 3, 4B, 2321-2324 (2000).

[2] S. Mahapatra, A.M. Ionescu, K. Banerjee, A quasianalytical SET model for few electron circuit simulation, IEEE 
Electron Device Lett., 23, 366-368 (2002).

[3] C. Wasshuber, Computational Electronics, New York: Springer-Verlag, (2002).

[4] R.H. Chen, A.N. Karotkov, K.K. Likharev, A new logic family based on single electron transistors, Proceedings of Device Res. Conf., 44-45, (1995).

[5] Y.S. Yu, J.H. Oh, S.W. Hawng, D. Ahn, Implementation of single electron circuit simulation by SPICE: KOSEC-SPICE, Proceedings of Asia Pacific Workshop on fundamental application of advanced semiconductor device (AWAD 2000), 85-90 (2000).

[6] K.K. Likharev, SETTRAN - a simulator for single lectron transistor, [On-line]. Available:

http://hana.physics.sunysb.edu/set/softw are.
[7] H. Inokawa, Y. Takashi, A compact analytical model for asymmetrical single-electron transistors, IEEE Transactions on Electron Devices, 50, 2, 455-461 (2003).

[8] S. Datta, Quantum Transport: Atom to Transistor, Cambridge University Press, (2005).

[9] D.S. Hien, Development of quantum device simulator, NEMO-VN2, Proceedings of fifth IEEE international symposium on electronic design, test and applications, DELTA-2010, Ho Chi Minh City, 170-173, (2010).

[10] K. Matsumoto, M. Ishii, K. Segawa, Y. Oka, B.J. Vartanian, J.S. Harris, Room temperature operation of a single electron transistor made by the scanning tunneling microscope nanooxidation process for the $\mathrm{TiO} / \mathrm{Ti}$ system, Appl. Phys. Lett., 68, 34: doi:101063/1, 116747 (1996). 